\title{
Development of a rapid column-switching LC-MS/MS method for the quantification of THCCOOH and THCCOOH-glucuronide in whole blood for assessing cannabis consumption frequency
}

\author{
Marianne Hädener $^{1}$ • Wolfgang Weinmann ${ }^{1}$ • Stefan Schürch ${ }^{2}$ • Stefan König ${ }^{1}$
}

Received: 18 November 2015 /Revised: 24 December 2015 / Accepted: 4 January 2016

(C) Springer-Verlag Berlin Heidelberg 2016

\begin{abstract}
The concentration of 11-nor-9-carboxy- $\Delta^{9}$-tetrahydrocannabinol (THCCOOH) in whole blood is used as a parameter for assessing the consumption behavior of cannabis consumers. The blood level of THCCOOH-glucuronide might provide additional information about the frequency of cannabis use. To verify this assumption, a column-switching liquid chromatography-tandem mass spectrometry (LC-MS/ MS) method for the rapid and direct quantification of free and glucuronidated $\mathrm{THCCOOH}$ in human whole blood was newly developed. The method comprised protein precipitation, followed by injection of the processed sample onto a trapping column and subsequent gradient elution to an analytical column for separation and detection. The total LC run time was $4.5 \mathrm{~min}$. Detection of the analytes was accomplished by electrospray ionization in positive ion mode and selected reaction monitoring using a triple-stage quadrupole mass spectrometer. The method was fully validated by evaluating the following parameters: linearity, lower limit of quantification, accuracy and imprecision, selectivity, extraction efficiency, matrix effect, carry-over, dilution integrity, analyte stability, and re-injection reproducibility. All acceptance criteria were analyzed and the predefined criteria met. Linearity ranged from 5.0 to $500 \mu \mathrm{g} / \mathrm{L}$ for both analytes. The method was successfully applied to whole blood samples from a large
\end{abstract}

Marianne Hädener

marianne.haedener@irm.unibe.ch

1 Institute of Forensic Medicine, University of Bern, Bühlstrasse 20, 3012 Bern, Switzerland

2 Department of Chemistry and Biochemistry, University of Bern, Freiestrasse 3, 3012 Bern, Switzerland collective of cannabis consumers, demonstrating its applicability in the forensic field.

Keywords $\mathrm{THCCOOH} \cdot \mathrm{THCCOOH}$-glucuronide . Column-switching chromatography $\cdot$ LC-MS/MS $\cdot$ Whole blood · DUI

\section{Introduction}

Cannabis is the most widely abused illicit drug worldwide [1]. Not surprisingly, roadside surveys have demonstrated that driving under the influence of cannabis (DUIC) is a common and widespread occurrence [2-5]. Cannabis consumption has been shown to have impairing effects on cognitive functions and psychomotor skills related to driving and to be associated with an elevated accident risk [6-9]. Thus, DUIC has severe implications on global road safety and is considered a serious criminal offense in many countries [10].

$\Delta^{9}$-Tetrahydrocannabinol (THC), the major psychoactive component of cannabis, is extensively metabolized in humans, mainly by liver enzymes. Phase I biotransformation involves hydroxylation to active 11-hydroxy-THC (11-OHTHC), followed by oxidation to inactive 11-nor-9-carboxyTHC (THCCOOH). Further biotransformation via phase II glucuronidation produces hydrophilic conjugates that are easily excreted [11].

Due to its long elimination half-life [11], THCCOOH accumulates in the blood upon regular cannabis use [12-15] and has therefore been proposed as diagnostic marker to distinguish between occasional and heavy users $[16,17]$. In Switzerland, a free THCCOOH blood level of $40 \mu \mathrm{g} / \mathrm{L}$ is currently used as cutoff for the classification of impaired drivers as heavy users, as recommended by Fabritius et al. $[17,18]$. Since chronic cannabis consumption may imply a 
long-term unfitness to drive, these drivers suspected of heavy cannabis misuse are required to undergo medical assessment of their fitness to drive, even if no active THC was detected in their blood. As a road safety measure, unfit drivers face a suspension of their driver's license by administrative authorities. After a proven period of abstinence and regular medical checkups, the driver's license may be re-issued.

In the study conducted by Fabritius et al. [17], the $40 \mu \mathrm{g} / \mathrm{L}$ cutoff for free THCCOOH showed a low sensitivity, implying that its ability to correctly identify heavy users is rather poor. Since THCCOOH in blood is extensively glucuronidated [19], we hypothesize that the free THCCOOH blood level is not solely determined by the consumption frequency, but is also dependent on the individual glucuronidation rate. Indeed, several studies have shown that the ratio of conjugated to free THCCOOH in plasma or blood was variable between participants at a given time point following controlled THC administration $[12,15,19,20]$. In our view, these findings suggest that there are interindividual differences in the $\mathrm{THCCOOH}$ glucuronidation rate which could be attributed to genetic polymorphisms of the glucuronosyltransferase enzymes catalyzing the glucuronidation of cannabinoids [21, 22]. Furthermore, as reported for THCCOOH [12-15], serum, plasma, and blood levels of THCCOOH-glucuronide have been found to be higher in heavy cannabis users than in occasional users $[12,14,15]$. Therefore, we assume that THCCOOH-glucuronide blood concentrations could serve as an additional marker for assessing the frequency of cannabis use and that the recognition of heavy users could be improved if both the free and glucuronidated THCCOOH blood levels are taken into account.

Numerous analytical methods for the quantification of THC and its metabolites in biological fluids have been developed, which are mostly based on gas chromatography (GC) or liquid chromatography (LC) coupled to mass spectrometry (MS) $[23,24]$. However, the direct and simultaneous determination of THCCOOH and its glucuronide by GC-MS is not possible as glucuronides are thermally unstable and nonvolatile $[25,26]$. To quantify THCCOOH-glucuronide by GC-MS, free THCCOOH is analyzed first and then the glucuronide is hydrolyzed to measure total $\mathrm{THCCOOH}$. The amount of THCCOOH-glucuronide is calculated as the difference between total and free THCCOOH [12]. Since hydrolysis can be variable and/or incomplete, this procedure can lead to ambiguous results $[27,28]$. The use of LC-MS/MS eliminates the need of costly and time-consuming alkaline and/or enzymatic glucuronide hydrolysis, enabling direct measurement of free and glucuronidated $\mathrm{THCCOOH}$. As native and isotopically labeled $\mathrm{THCCOOH}$-glucuronide standards have become available only recently, few LC-MS/MS for quantifying THCCOOH-glucuronide in biological fluids exist [25, 29-33]. Schwope et al. [25] and Gronewold et al. [31] reported the only two existing methods for simultaneously measuring free and glucuronidated $\mathrm{THCCOOH}$ in whole blood, along with free and glucuronidated THC, 11-OH-THC, cannabinol, and cannabidiol. Sample preparation consisted of protein precipitation followed by solid-phase extraction [25] or liquid-liquid extraction [31], and chromatographic separation of the analytes was accomplished in 16 and $10 \mathrm{~min}$, respectively.

In this work, a validated column-switching LC-MS/MS method for the direct and simultaneous quantification of $\mathrm{THCCOOH}$ and $\mathrm{THCCOOH}$-glucuronide in whole blood is reported. Key factors are a low sample volume, a straightforward sample preparation procedure, and a fast chromatography. This novel high-throughput method is used to investigate whether THCCOOH-glucuronide whole blood concentration complements free $\mathrm{THCCOOH}$ level for assessing cannabis consumption frequency.

\section{Experimental}

\section{Materials}

Standard solutions of THCCOOH, THCCOOH-glucuronide, and their tri-deuterated analogs (carrying a tri-deuterated methyl group at the end of the pentyl side chain) were purchased at a concentration of $100 \mu \mathrm{g} / \mathrm{mL}$ from Cerilliant Corporation (Round Rock, TX, USA). Acetonitrile (HPLC gradient grade, $99.9 \%$ ) was obtained from Acros Organics (Chemie Brunschwig, Basel, Switzerland), methanol (absolute, HPLC grade) from Biosolve (Chemie Brunschwig, Basel, Switzerland), and formic acid (analytical grade, $98 \%$ ) from Fluka (Sigma-Aldrich, Buchs, Switzerland). Water was purified in-house with a Milli-Q water system from Millipore (Zug, Switzerland). Precision pipettes from Gilson (Mettmenstetten, Switzerland) were used for handling of all solutions and samples. Blank human blood was obtained from the blood donor center in Bern, Switzerland, and was analyzed prior to its use to verify absence of analytes. Authentic blood samples were collected in tubes containing potassium fluoride as anticoagulant. Sample preparation was carried out in 96 deep-well plates (round bottom, $1 \mathrm{~mL}$ ) obtained from Corning (Chemie Brunschwig, Basel, Switzerland) and sealed with silicone mats from Axygen (Chemie Brunschwig, Basel, Switzerland).

\section{Preparation of calibration and quality control samples}

Working solutions for preparing calibration and quality control (QC) samples were obtained via dilution of the reference standard solutions in methanol. Separate dilution series were used for the preparation of calibration and QC working solutions. All working solutions were stored at $-20{ }^{\circ} \mathrm{C}$ in polypropylene tubes. Adding $5 \mu \mathrm{L}$ of working solution to $95 \mu \mathrm{L}$ of blank blood created calibration samples at 5, 10, 25, 50, 100, 
250, and $500 \mu \mathrm{g} / \mathrm{L}$ and QC samples at 5, 15, 125, and $400 \mu \mathrm{g} /$ L. Calibration and QC samples were freshly prepared in 96 deep-well plates on each day of analysis.

\section{Sample preparation}

Protein precipitation was performed in 96 deep-well plates by adding $300 \mu \mathrm{L}$ of cold acetonitrile containing the deuterated internal standards $\left(50 \mu \mathrm{g} / \mathrm{L} \mathrm{THCCOOH}-d_{3}\right.$ and $20 \mu \mathrm{g} / \mathrm{L}$ THCCOOH- $d_{3}$-glucuronide) to $100 \mu \mathrm{L}$ of blood (calibration, QC, or unknown sample). Subsequently, the well plates were sealed, vortexed for $10 \mathrm{~min}$, and centrifuged (Rotanta $460 \mathrm{R}$, Hettich, Bäch, Switzerland) for $35 \mathrm{~min}$ at $4234 \mathrm{~g}$ and $4{ }^{\circ} \mathrm{C}$. The plates were placed in a cooled autosampler, and $40 \mu \mathrm{L}$ of each supernatant was injected into the LC-MS/MS system.

\section{Liquid chromatography}

Chromatography equipment consisted of an UltiMate ${ }^{\circledR} 3000$ HPLC system (Dionex, Olten, Switzerland) including a SRD3600 solvent rack, two HPG-3200A binary pumps, an ISO$3100 \mathrm{~A}$ isocratic pump, a TCC-3100 thermostatted column compartment with a built-in 10-port switching valve and a WPS-3000TSL thermostatted plate autosampler set to a temperature of $8{ }^{\circ} \mathrm{C}$.

A schematic representation of the chromatographic setup is shown in Fig. 1. The prepared samples were loaded with a $300 \mu \mathrm{L} / \mathrm{min}$ flow (acetonitrile/water/formic acid, 40/60/0.1; $v / v /$ v) onto a trapping column (Mercury Synergy ${ }^{\mathrm{TM}} 4 \mu \mathrm{m}$ Polar RP $80 \AA, 10 \times 2.0 \mathrm{~mm}$, Phenomenex, Torrance, CA, USA) and diluted via a T-union with an aqueous flow containing $0.1 \%$ formic acid in order to enhance the loading and trapping step efficiencies. After $1 \mathrm{~min}$, the valve was switched and the trapping column was connected to the analytical column in backflush direction. Analytical separation was achieved on a $30 \times 2.1 \mathrm{~mm}$ column packed with $2.6 \mu \mathrm{m}$ core-shell particles (Kinetex ${ }^{\mathrm{TM}} \mathrm{PFP}$ $100 \AA$, Phenomenex, Torrance, CA, USA), equipped with a guard column (KrudKatcher Ultra, Phenomenex, Torrance, CA, USA) and heated to $40^{\circ} \mathrm{C}$. Gradient elution of the analytes from the trapping to the analytical column was performed with $0.1 \%$ formic acid in water as mobile phase $\mathrm{A}$ and $0.1 \%$ formic acid in acetonitrile as mobile phase B. The gradient was raised from 30 to $97.5 \% \mathrm{~B}$ in $1 \mathrm{~min}$ and kept isocratic for one more minute. Then, the valve was switched back to the loading position and both columns were re-equilibrated to the initial mobile phase conditions, resulting in a total run time of $4.5 \mathrm{~min}$. The mobile phase composition and gradient program for each pump are given in detail in Table 1.

\section{Mass spectrometry}

Mass spectrometric data were acquired on a 3200 QTRAP $^{\circledR}$ triple-stage quadrupole mass spectrometer (AB SCIEX,
Brugg, Switzerland) operated in positive electrospray ionization (ESI) and selected reaction monitoring (SRM) modes. The instrument parameters for ionization were as follows: ion source voltage, $5250 \mathrm{~V}$; source temperature, $650^{\circ} \mathrm{C}$; curtain gas, 25; collision gas, 5; gas 1, 40; and gas 2, 40 (arbitrary units for the gas settings). Quadrupole one $\left(\mathrm{Q}_{1}\right)$ and quadrupole three $\left(\mathrm{Q}_{3}\right)$ were set to unit resolution. THCCOOH, THCCOOH-glucuronide as well as its deuterated analog were measured with two SRM transitions each, whereas for THCCOOH- $d_{3}$, only one transition was monitored. SRM conditions were optimized by direct infusion of each analyte and internal standard via syringe pump and are specified in Table 2.

\section{Data analysis}

Analyst software version 1.5.1 (AB SCIEX, Brugg, Switzerland, 2010) was used for data acquisition and processing. Calibration curves were generated by calculating the peak area ratios of analytes to corresponding internal standards for each analyte concentration $(x)$. Linear least-squares regression with a $1 / x$ weighting factor was employed for both analytes. Bland-Altman analysis was performed using GraphPad Prism 6.05 for Windows (GraphPad Software, La Jolla, CA, USA, 2014).

\section{Validation}

The developed method was validated in terms of linearity, intra- and inter-assay accuracy and imprecision, lower limit of quantification (LLOQ), selectivity, extraction efficiency, matrix effect, carry-over, dilution integrity, analyte stability, and re-injection reproducibility. Method validation was performed according to international guidelines on bioanalytical method validation [34, 35].

Linearity of each analyte was determined with seven concentration levels $(5,10,25,50,100,250$, and $500 \mu \mathrm{g} / \mathrm{L})$ prepared in duplicate on three different days. Calibration curves were fit by unweighted linear least-squares regression and linear least-squares regression employing $1 / x$ and $1 / x^{2}$ weighting. The calibration models were evaluated based on the percentage relative error $(\% \mathrm{RE})$ which compares the concentration determined from the regression equation with the nominal concentration. The \%RE values were plotted versus nominal concentration and the sum of absolute \%RE values was calculated. The most appropriate calibration model was defined as that producing the narrowest distribution of the $\% \mathrm{RE}$ around the concentration axis and the lowest \%RE sum across the entire concentration range [36]. Calibrators were required to quantify within $\pm 15 \%$ of the target value $( \pm 20 \%$ for LLOQ), and correlation coefficients $(r)$ should exceed 0.99 . 
Fig. 1 Schematic representation of the column-switching LC-MS/ MS system. a Loading onto the trapping column and $\mathbf{b}$ gradient elution to the analytical column. Arrows indicate flow direction
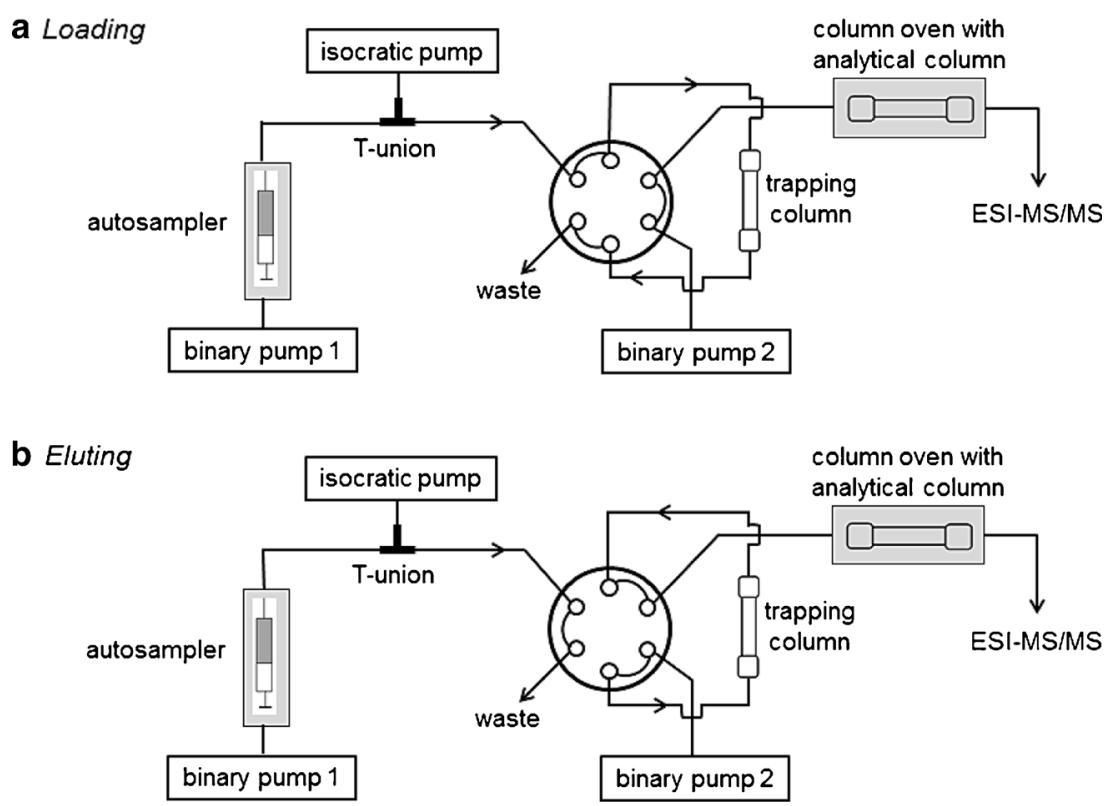

Accuracy and imprecision of the method were assessed at low, mid, and high QC levels $(15,125$, and $400 \mu \mathrm{g} / \mathrm{L}$ ) as well as at the LLOQ level. Intraassay accuracy and imprecision were determined from six replicates per level in a single run. For the evaluation of the inter-assay accuracy and imprecision, six replicates of each QC level were prepared and analyzed on three different days ( $n$ total $=18$ ). QC concentrations were calculated from freshly prepared calibration curves. Accuracy was determined as the percentage of the mean concentration of all replicates from the corresponding nominal value. Imprecision was defined as percent coefficient of variation ( $\% \mathrm{CV}$ ) of the calculated concentrations. The mean concentration at each QC level should be within $\pm 15 \%$ of the nominal concentration $( \pm 20 \%$ for LLOQ), and the imprecision should not exceed $15 \% \mathrm{CV}$ (20\% CV for LLOQ).

Selectivity was assessed by testing blank blood from six individual sources for the absence of signals interfering with the peaks of both analytes and internal standards. In addition, selectivity was evaluated by spiking the different blank blood samples to the LLOQ level. Interference from endogenous compounds was considered insignificant if any response in the blank sample was less than $20 \%$ of the LLOQ and $5 \%$

Table 1 Mobile phase composition and gradient conditions for all HPLC pumps

\begin{tabular}{|c|c|c|c|c|c|c|c|}
\hline \multirow[t]{3}{*}{ Time (min) } & \multicolumn{3}{|c|}{ Analytical column (AC) } & \multicolumn{4}{|c|}{ Trapping column (TC) } \\
\hline & \multicolumn{3}{|c|}{ Binary pump 1} & \multicolumn{4}{|c|}{ Binary pump 2, isocratic pump (IP) } \\
\hline & $\% \mathrm{~B}$ & Flow $(\mu \mathrm{L} / \mathrm{min})$ & Comments & $\% \mathrm{~B}$ & Flow $(\mu \mathrm{L} / \mathrm{min})$ & Flow IP $(\mu \mathrm{L} / \mathrm{min})$ & Switching valve \\
\hline 0.0 & 30 & 400 & Start MS, start pumps & 40 & 300 & 800 & $\begin{array}{l}\mathrm{TC} \rightarrow \text { waste } \\
\mathrm{AC} \rightarrow \text { MS (loading) }\end{array}$ \\
\hline 1.0 & 30 & 400 & Start gradient & 40 & 300 & 800 & $\mathrm{TC} \rightarrow \mathrm{AC} \rightarrow \mathrm{MS}$ (eluting) \\
\hline 1.2 & $\downarrow$ & 400 & & 40 & 300 & 800 & \\
\hline 1.3 & & 400 & & 40 & 20 & 20 & \\
\hline 2.0 & 97.5 & 400 & & 40 & 20 & 20 & \\
\hline 2.9 & 97.5 & 400 & & 40 & 20 & 20 & \\
\hline 3.0 & 97.5 & 400 & & 40 & 300 & 800 & $\begin{array}{l}\mathrm{TC} \rightarrow \text { waste } \\
\mathrm{AC} \rightarrow \mathrm{MS}\end{array}$ \\
\hline 3.1 & 30 & 400 & & 40 & 300 & 800 & Re-equilibrating \\
\hline 4.5 & 30 & 400 & & 40 & 300 & 800 & \\
\hline
\end{tabular}


Table 2 Optimized MS/MS parameter settings for each of the monitored SRM transitions. Italic masses denote quantifier transitions

\begin{tabular}{|c|c|c|c|c|c|c|c|}
\hline Analyte & $\mathrm{Q}_{1} \operatorname{mass}(m / z)$ & $\mathrm{Q}_{3} \operatorname{mass}(m / z)$ & Dwell time (ms) & $\mathrm{DP}(\mathrm{V})$ & $\mathrm{EP}(\mathrm{V})$ & $\mathrm{CE}(\mathrm{eV})$ & $\mathrm{CXP}(\mathrm{V})$ \\
\hline \multirow[t]{2}{*}{ THCCOOH } & 345.2 & 327.2 & 60 & 40 & 7 & 20 & 4 \\
\hline & 345.2 & 299.2 & 30 & 40 & 7 & 28 & 4 \\
\hline THCCOOH$-d_{3}$ & 348.2 & 330.2 & 30 & 40 & 7 & 20 & 4 \\
\hline \multirow[t]{2}{*}{ THCCOOH-glucuronide } & 521.2 & 327.2 & 60 & 50 & 4 & 32 & 4 \\
\hline & 521.2 & 345.2 & 60 & 50 & 4 & 20 & 4 \\
\hline \multirow[t]{2}{*}{ THCCOOH- $d_{3}$-glucuronide } & 524.2 & 330.2 & 30 & 50 & 4 & 32 & 4 \\
\hline & 524.2 & 348.2 & 30 & 50 & 4 & 20 & 4 \\
\hline
\end{tabular}

$D P$ declustering potential, $E P$ entrance potential, $C E$ collision energy, $C X P$ collision cell exit potential

of the internal standard response and if both analytes in the LLOQ samples quantified within $\pm 20 \%$ of the nominal concentrations.

Matrix effects were examined qualitatively by employing the post-column infusion method. A methanolic solution containing the analytes and their internal standards at a concentration of $1 \mu \mathrm{g} / \mathrm{mL}$ each was infused at a constant flow rate of $15 \mu \mathrm{L} / \mathrm{min}$ via a T-union into the HPLC effluent during the chromatographic analysis of a blank blood extract. The signals of the selected ion transitions were examined for any suppression or enhancement over the entire chromatographic run.

Extraction efficiencies were determined at low and high QC concentrations ( $n=6$ for each concentration) and were expressed as the mean cannabinoid peak area of samples spiked before protein precipitation divided by the mean peak area of processed blank samples that were spiked after protein precipitation.

Carry-over was assessed in duplicate by injecting a blank sample immediately after the highest calibrator. The response in the blank specimen was required to be $\leq 20 \%$ of the LLOQ and $\leq 5 \%$ of the internal standard response to demonstrate absence of carry-over.

Dilution integrity was evaluated by diluting blood samples fortified with both analytes at two concentrations (2500 and $1000 \mu \mathrm{g} / \mathrm{L}, n=6$ each) with blank blood to achieve 1:10 ( $/ / v)$ dilution. Dilution integrity was proven if specimens could be quantified with acceptable imprecision $(\leq 15 \% \mathrm{CV})$ and accuracy $( \pm 15 \%)$.

Matrix stability was only investigated for THCCOOH-glucuronide, since the stability of $\mathrm{THCCOOH}$ in whole blood under different storage conditions has already been demonstrated during validation of our previously developed LCMS/MS method for the quantification of THC, 11-OH-THC, and $\mathrm{THCCOOH}$ [37]. Stability of THCCOOH-glucuronide was examined at low and high QC concentrations under four storage conditions $(n=6$ for each concentration and condition): 2 days at room temperature (RT), 6 days at $4{ }^{\circ} \mathrm{C}$, 3 months at $-20^{\circ} \mathrm{C}$, and two freeze-thaw cycles $(18 \mathrm{~h}$ freeze at $-20^{\circ} \mathrm{C}, 6 \mathrm{~h}$ thaw at RT). QC working solutions containing only THCCOOH-glucuronide were used for preparation of the stability samples. After storage, samples were analyzed against a freshly prepared calibration curve and the calculated concentrations were compared to the concentrations determined before storage ( $t=0$ value). Samples were considered to be stable if their concentrations were within $\pm 15 \%$ of the initial values.

Re-injection reproducibility was assessed with six replicates of each QC level. These samples were analyzed immediately after sample preparation and were then re-injected after storage at $4{ }^{\circ} \mathrm{C}$ for 8 days and quantified against the re-injected calibration curve. Reproducibility was acceptable if reinjected samples quantified within $\pm 15 \%$ of the initially measured value.

\section{Application to forensic cases}

The presented method was applied to 926 whole blood specimens which were obtained from drivers suspected of DUI and were THCCOOH positive by our routinely used LCMS/MS method [37]. During the time between the routine measurement and the reanalysis with the presented method (3 to 12 months), the samples were stored at $-20{ }^{\circ} \mathrm{C}$. Each LC-MS/MS run incorporated two calibration curves (one at the beginning and one at the end), QC samples at three concentrations, one blank sample, one zero sample (blank blood processed with internal standard), and between 38 and 246 unknown samples. The number of QC samples was chosen based on the number of unknown samples and amounted to at least $5 \%$ of the unknowns (or at least two replicates per QC level, whichever number was higher). Using two sets of calibration samples per run compensated for any differences in method performance that might have occurred across the run. Both sets of calibration samples were used to calculate the calibration curve. At least one of the calibrators at each level was required to quantify within $\pm 15 \%$ of the target value, and the correlation coefficient $r$ should exceed 0.99 . Incurred sample reanalysis was performed with a random selection of 60 samples to verify the reliability and reproducibility of the 
analyte concentrations in authentic samples after storage at $-20{ }^{\circ} \mathrm{C}$ for 3 to 4 months. The difference between the initial concentration and the concentration measured during reanalysis should not exceed $20 \%$ of their mean for at least two thirds of the repeated samples.

\section{Results and discussion}

\section{Method performance}

We have developed a method for the simultaneous quantification of THCCOOH and THCCOOH-glucuronide in whole blood using a column-switching chromatographic approach to minimize sample preparation and analytical run time. In recent years, numerous publications have demonstrated the great potential of column-switching techniques for the analysis of drugs in complex biological matrices [37-41]. The use of a trapping column for sample cleanup and concentration and an analytical column for separation and detection allowed us to prepare blood samples by a simple protein precipitation step. Since a large volume could be injected without compromising the performance of the analytical column, sample preconcentration by evaporation and reconstitution was not necessary. Employing two columns, each containing a different stationary phase, provided sufficient selectivity to obtain excellent separation of the two analytes within only $4.5 \mathrm{~min}$. Average retention times were $2.16 \mathrm{~min}(0.6 \% \mathrm{CV})$ for THCCOOH-glucuronide and $2.39 \mathrm{~min}(0.7 \% \mathrm{CV})$ for $\mathrm{THCCOOH}$ (Fig. 2). The extracted ion chromatogram of THCCOOH also showed a peak at $2.16 \mathrm{~min}$ which corresponded to the THCCOOH fragment originating from in-source decay of the glucuronide during the ionization process. Since the two peaks were baseline separated, there was no contribution of the in-source decay of THCCOOHglucuronide to the intrinsic amount of free $\mathrm{THCCOOH}$.

\section{Validation}

The method was validated according to the criteria detailed in the "Experimental" section.

Inspection of relative percentage errors indicated that linear least-squares regression with a $1 / x$ weighting factor was the most appropriate calibration model. LLOQ, linearity, and calibration results are presented in Table 3. The LLOQ, defined as the lowest concentration quantifiable with acceptable accuracy $( \pm 20 \%)$ and imprecision $(\leq 20 \% \mathrm{CV})$, was determined to be $5 \mu \mathrm{g} / \mathrm{L}$ for both analytes. The accuracy and imprecision results at the LLOQ are specified in Table 4. Calibration curves were linear up to $500 \mu \mathrm{g} / \mathrm{L}$ with acceptable correlation coefficients $r$ ( $1 / x$ weighting). The back-calculated concentrations of the calibration standards were within $\pm 8 \%$ of the nominal value.
Accuracy and imprecision were evaluated at four concentrations across the linear dynamic range. The results of these analyses are summarized in Table 4. Both analytes matched the validation criteria. Accuracy ranged from 92.0 to $108.0 \%$, and imprecision was determined to be less than $13.5 \% \mathrm{CV}$ for the two analytes at each QC level.

Selectivity proved to be sufficient. No endogenous interferences were observed for the monitored SRM transitions in any of the tested blank blood samples, and LLOQ quantification was within $18.4 \%$ for $\mathrm{THCCOOH}$ and $11.6 \%$ for THCCOOH-glucuronide, respectively, in all six whole blood sources. Extracted ion chromatograms for a blank blood specimen, a blank blood specimen spiked with analytes at the LLOQ level, and an authentic blood specimen from a cannabis consumer are shown in Fig. 2.

The effect of co-eluting matrix components on the ionization of the analytes was examined qualitatively by the post-column infusion technique. Figure 3 shows the responses obtained after injection of an extracted blank blood sample. For both analytes and internal standards, an abrupt change of the ion intensity was observed between 1.2 and $1.5 \mathrm{~min}$, which was most likely caused by the reduction of the flow rate through the trapping column (Table 1) happening at that time. The severe ion suppression effects detected after $2.3 \mathrm{~min}$, however, were most probably produced by lipophilic matrix compounds eluting from the column during the isocratic hold at $97.5 \% \mathrm{~B}$ at the end of the gradient. After $3.1 \mathrm{~min}$, when the columns were reequilibrated, signal intensities gradually returned to their initial value. While no ion suppression or enhancement was observed at the retention time of $\mathrm{THCCOOH}$-glucuronide and its deuterated analog $(2.16 \mathrm{~min})$, the retention time of $\mathrm{THCCOOH}$ (2.39 min) coincided with the region of ion suppression. The reduced response of THCCOOH was, however, compensated for by its internal standard, since their signal suppression profiles were close to identical. Thus, quantification was not adversely affected.

Extraction efficiencies for the analytes and their deuterium-labeled analogs were reproducible and reasonably high, ranging from 67.5 to $85.0 \%$. Detailed data are reported in Table 5.

There was no evidence of carry-over for both analytes and their internal standards. Any signal present in blank specimens injected after the highest calibration sample was insignificant.

Dilution integrity was maintained at ten times dilution with blank whole blood. Both analytes were quantified within $10.0 \%$ of the theoretical concentrations and with an imprecision less than $12.2 \% \mathrm{CV}$.

THCCOOH stability in spiked whole blood samples was previously evaluated in our laboratory [37]. THCCOOH was stable for $6 \mathrm{~h}$ at RT and three freeze-thaw cycles $(20 \mathrm{~h}$ freeze, $4 \mathrm{~h}$ thaw at RT). Schwope et al. [25] found that $\mathrm{THCCOOH}$ was stable in spiked blood for $16 \mathrm{~h}$ at RT and $72 \mathrm{~h}$ at $4{ }^{\circ} \mathrm{C}$ and when subjected to three freeze-thaw cycles ( $23 \mathrm{~h}$ freeze, $1 \mathrm{~h}$ thaw at RT). Long- 

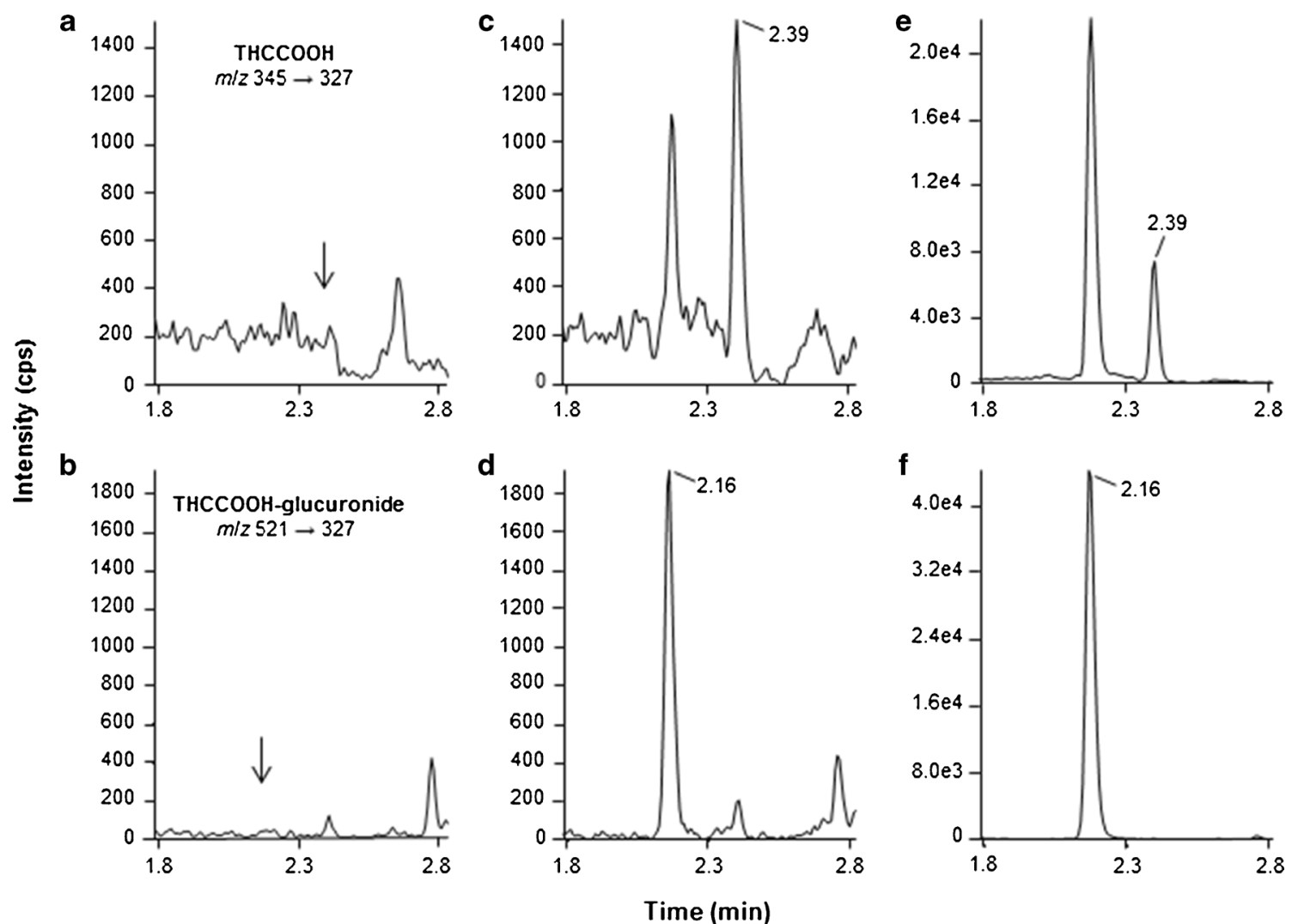

Fig. 2 SRM ion chromatograms of $\mathbf{a}, \mathbf{b}$ extracted blank whole blood (arrows indicate expected retention times), $\mathbf{c}, \mathbf{d}$ analytes at the lowest calibration level $(5 \mu \mathrm{g} / \mathrm{L}$ each), and e, fan authentic whole blood specimen from a cannabis consumer (THCCOOH, $97.6 \mu \mathrm{g} / \mathrm{L} ; \mathrm{THCCOOH}$-glucuronide, $296 \mu \mathrm{g} / \mathrm{L}$ )

term stability of THCCOOH in authentic whole blood samples was investigated by Scheidweiler et al. [42] and was reported to be 1 month at $4{ }^{\circ} \mathrm{C}$ and 6 months at $-20^{\circ} \mathrm{C}$.

Quantification of THCCOOH in THCCOOH-glucuronide stability samples prior to storage demonstrated that degradation of the glucuronide during sample processing and injection was minimal. Mean percentage of glucuronide hydrolysis was $1.23 \pm 0.22 \%(n=6)$. Since pure THCCOOH-glucuronide QC solutions were found to contain $0.75 \pm 0.05 \%$ THCCOOH $(n=4)$, glucuronide hydrolysis occurring during extraction was actually even more insignificant. THCCOOH-glucuronide was stable under all storage conditions tested ( 2 days at RT, 6 days at $4{ }^{\circ} \mathrm{C}$, 3 months at $-20{ }^{\circ} \mathrm{C}$, two freeze-thaw cycles) with mean concentrations showing less than $12.9 \%$ deviation from their initial values. Our observations on glucuronide stability are in agreement with the findings reported by Schwope et al. [25] and Scheidweiler et al. [42].

Re-injection reproducibility met acceptance criteria. Measured concentrations for sample extracts after storage at $4{ }^{\circ} \mathrm{C}$ for 8 days were within $10.2 \%$ of the initial values.

\section{Proof of method}

The method was applied to 926 authentic blood samples from a wide variety of cannabis consumers. QC samples, which were incorporated in each assay run, were quantified with acceptable accuracy and imprecision, thus demonstrating the method's robustness. Intra- and inter-assay accuracy ranged from 87.0 to $113.3 \%(n=2-8)$ and $91.7-104.9 \%(n=32)$, respectively. Intra- and inter-assay imprecision was less than
Table 3 Limits of quantification, linear ranges, and calibration results $(1 / x$ weighting) for the determination of $\mathrm{THCCOOH}$ and THCCOOH-glucuronide in whole blood by LC-MS/MS

\begin{tabular}{llllll}
\hline Analyte & $\begin{array}{l}\text { LLOQ } \\
(\mu \mathrm{g} / \mathrm{L})\end{array}$ & $\begin{array}{l}\text { Linear range } \\
(\mu \mathrm{g} / \mathrm{L})\end{array}$ & \multicolumn{1}{l}{$\begin{array}{l}\text { Slope } \pm \mathrm{SD} \\
(n=6)\end{array}$} & $\begin{array}{l}y \text { intercept } \pm \mathrm{SD} \\
(n=6)\end{array}$ & $r \pm \mathrm{SD}(n=6)$ \\
\hline THCCOOH & 5.0 & $5.0-500$ & $0.0057 \pm 0.0004$ & $0.0080 \pm 0.0072$ & $0.9984 \pm 0.0007$ \\
$\begin{array}{c}\text { THCCOOH- } \\
\text { glucuronide }\end{array}$ & 5.0 & $5.0-500$ & $0.0098 \pm 0.0012$ & $-0.0081 \pm 0.0081$ & $0.9985 \pm 0.0012$ \\
\hline
\end{tabular}


Table 4 Accuracy and imprecision data. Analyte concentrations of LLOQ and low, mid, and high QC samples were $5,15,125$, and $400 \mu \mathrm{g} / \mathrm{L}$, respectively

\begin{tabular}{|c|c|c|c|c|}
\hline \multirow[t]{2}{*}{ QC level } & \multicolumn{2}{|c|}{ Intra-assay $(n=6)$} & \multicolumn{2}{|c|}{ Inter-assay $(n=18)$} \\
\hline & Accuracy $(\%)$ & Imprecision (\% CV) & Accuracy $(\%)$ & Imprecision $(\% \mathrm{CV})$ \\
\hline \multicolumn{5}{|c|}{ THCCOOH } \\
\hline LLOQ & 108.0 & 9.3 & 104.0 & 13.5 \\
\hline Low & 96.7 & 5.5 & 97.3 & 6.2 \\
\hline Mid & 98.6 & 3.7 & 97.7 & 5.5 \\
\hline High & 105.5 & 3.8 & 102.3 & 6.6 \\
\hline \multicolumn{5}{|c|}{ THCCOOH-glucuronide } \\
\hline LLOQ & 92.0 & 4.3 & 98.0 & 10.2 \\
\hline Low & 93.3 & 5.0 & 94.7 & 6.3 \\
\hline Mid & 101.8 & 3.2 & 103.4 & 4.9 \\
\hline High & 106.0 & 3.5 & 104.0 & 6.3 \\
\hline
\end{tabular}

$8.8 \% \mathrm{CV}$ and $6.6 \% \mathrm{CV}$, respectively, for the two analytes at each QC level.

Median concentrations of the authentic blood specimens were $25.7 \mu \mathrm{g} / \mathrm{L}$ for $\mathrm{THCCOOH}$ (range $<5.0$ $166 \mu \mathrm{g} / \mathrm{L}$ ) and $87.1 \mu \mathrm{g} / \mathrm{L}$ (range $<5-869 \mu \mathrm{g} / \mathrm{L}$ ) for THCCOOH-glucuronide. Samples with analyte concentrations exceeding the highest calibration standard were diluted with blank blood (1:10) and re-analyzed. The vast majority of the samples showed concentrations within the calibration range $(92.8 \%$ for $\mathrm{THCCOOH}$ and $99.2 \%$ for $\mathrm{THCCOOH}-$ glucuronide), indicating that these ranges prove useful for analysis of forensic case samples.

The reliability of the method was further demonstrated by re-analyzing a subset of authentic samples, as it is common during incurred sample reanalysis [35]. The percentage difference between the original and re-

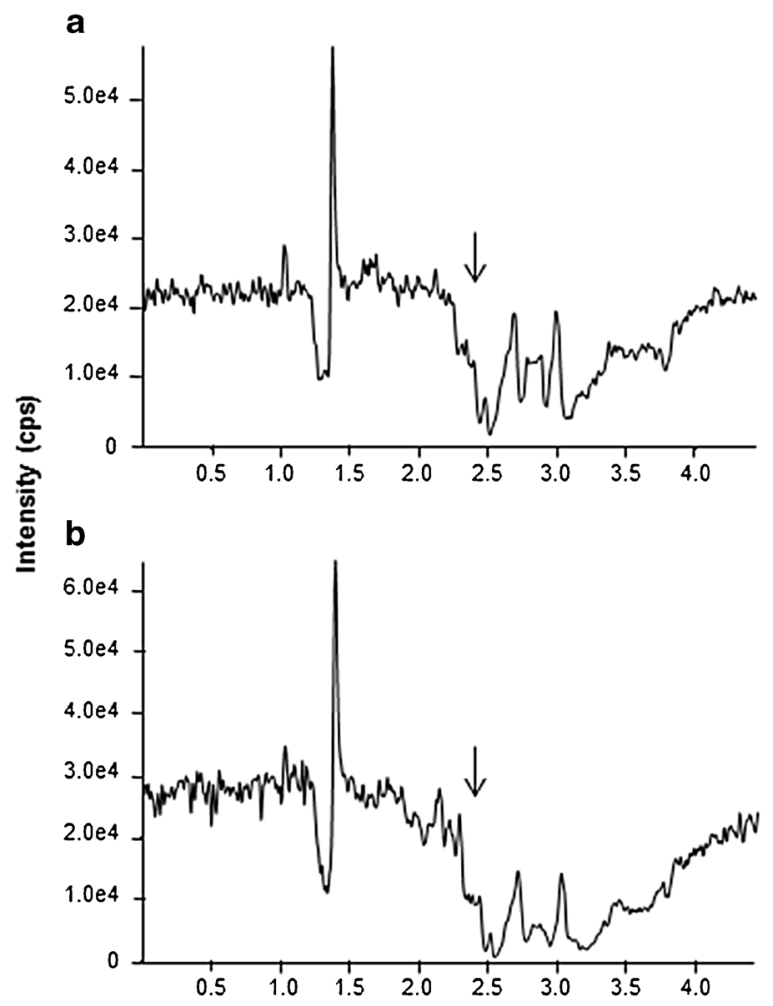

b

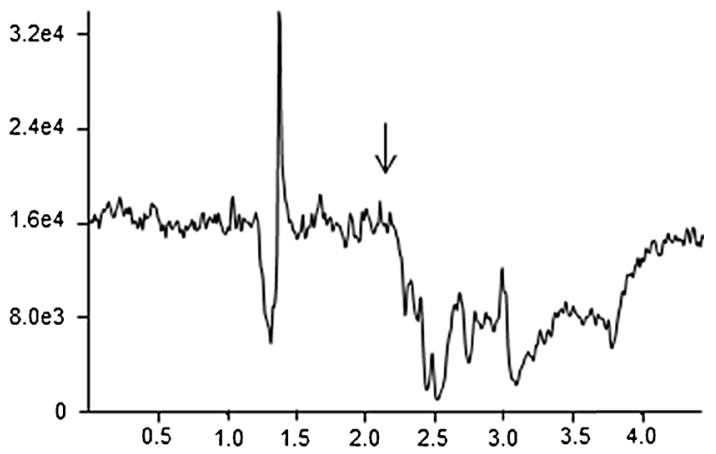

d

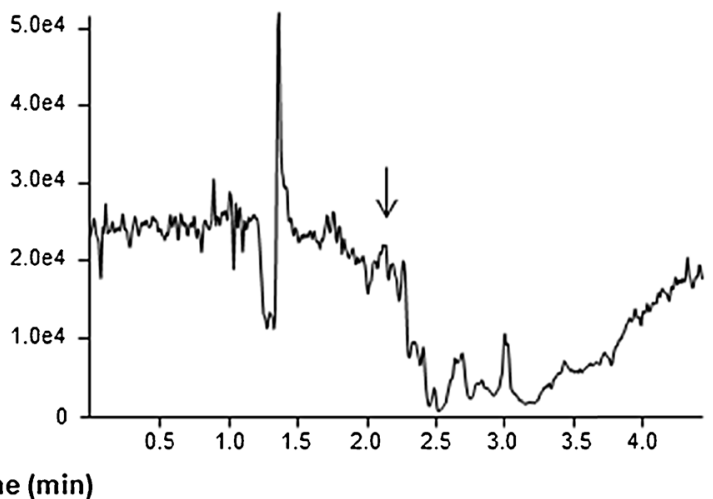

Fig. 3 Evaluation of matrix effects on a THCCOOH, b THCCOOH- $d_{3}$, $\mathbf{c}$ THCCOOH-glucuronide, and d THCCOOH- $d_{3}$-glucuronide by post-column infusion following injection of an extracted blank blood specimen. Arrows indicate expected retention times 
Table 5 Extraction efficiency for THCCOOH and THCCOOHglucuronide from whole blood. Analyte concentrations of low and high QC samples were 15 and $400 \mu \mathrm{g} / \mathrm{L}$, respectively

\begin{tabular}{lll}
\hline \multirow{2}{*}{ Analyte } & \multicolumn{2}{l}{ Extraction efficiency $(\%, n=6)$} \\
\cline { 2 - 3 } & Low & High \\
\hline THCCOOH & 69.0 & 69.1 \\
THCCOOH- $d_{3}$ & 67.5 & 75.2 \\
THCCOOH-glucuronide & 71.9 & 73.8 \\
THCCOOH- $d_{3}$-glucuronide & 77.0 & 85.0 \\
\hline
\end{tabular}

analyzed THCCOOH concentrations was within $20 \%$ for $78.3 \%$ of the repeated samples. For THCCOOHglucuronide, $83.3 \%$ of the repeats were within $20 \%$. Thus, both analytes met the predetermined criteria.

Authentic THCCOOH concentrations $(n=926)$ measured with the presented method were compared to those obtained with our previously published, routinely used LC-MS/MS method for determination of THC, 11-OH-THC, and THCCOOH in whole blood [37]. Bland-Altman analysis demonstrated good agreement between the two methods, with a bias close to zero $(-0.99 \mu \mathrm{g} / \mathrm{L})$ and $95 \%$ limit of agreement ranging from -12.29 to $10.31 \mu \mathrm{g} / \mathrm{L}$ (calculated as the mean difference $\pm 1.96 \mathrm{SD}$ ).

\section{Conclusions}

In this paper, a rapid LC-MS/MS method for the simultaneous analysis of THCCOOH and THCCOOHglucuronide in human whole blood is described. LCMS/MS enables direct quantification of free and glucuronidated $\mathrm{THCCOOH}$, avoiding time-intensive sample hydrolysis and derivatization, which simplifies result interpretation. The use of column-switching chromatography with on-line sample enrichment and purification allowed for a simple and fast sample preparation procedure and short analytical run time. The method was fully validated and proved to be robust, selective, accurate, and precise. It was successfully used on whole blood samples from a large collective of cannabis consumers, thus proving applicable and reliable in the forensic toxicological setting. The method will be employed to analyze blood samples from a controlled cannabis administration study and will provide pharmacokinetic data useful for assessing the suitability of free and glucuronidated $\mathrm{THCCOOH}$ as indicators of cannabis consumption frequency. In Swiss traffic policy, a reliable diagnostic marker for identifying heavy cannabis users is required in the context of driving aptitude assessments.
Acknowledgments The authors acknowledge the staff of the Forensic Toxicology laboratory for their technical assistance.

\section{Compliance with ethical standards}

Conflict of interest The authors declare that they have no competing interests.

\section{References}

1. United Nations Office on Drugs and Crime (UNODC) (2015) World drug report 2015. http://www.unodc.org/documents/ wdr2015/World_Drug_Report_2015.pdf. Accessed 28 Sept 2015.

2. European Monitoring Centre for Drugs and Drug Addiction (EMCDDA) (2012) Driving under the influence of drugs, alcohol and medicines in Europe - findings from the DRUID project. http://www.emcdda.europa.eu/attachements.cfm/att 192773 EN TDXA12006ENN.pdf. Accessed 08 Oct 2015.

3. Lacey JH, Kelley-Baker T, Voas RB, Romano E, Furr-Holden CD, Torres P, et al. Alcohol- and drug-involved driving in the United States: methodology for the 2007 National Roadside Survey. Eval Rev. 2011;35:319-53. doi:10.1177/0193841x11422446.

4. Beasley EE, Beirness DJ (2012) Alcohol and drug use among drivers following the introduction of immediate roadside prohibitions in British Columbia: findings from the 2012 roadside survey. http://www.pssg.gov.bc.ca/osmv/shareddocs/bc-roadsidereport2012.pdf. Accessed 08 Oct 2015

5. Davey J, Armstrong K, Martin P. Results of the Queensland 20072012 roadside drug testing program: the prevalence of three illicit drugs. Accid Anal Prev. 2014;65:11-7. doi:10.1016/j.aap.2013.12. 007.

6. Hartman RL, Huestis MA. Cannabis effects on driving skills. Clin Chem. 2013;59:478-92. doi:10.1373/clinchem.2012.194381.

7. Battistella G, Fornari E, Thomas A, Mall JF, Chtioui H, Appenzeller M, et al. Weed or wheel! FMRI, behavioural, and toxicological investigations of how cannabis smoking affects skills necessary for driving. PLoS ONE. 2013;8, e52545. doi:10.1371/ journal.pone.0052545.

8. Asbridge M, Mann R, Cusimano MD, Trayling C, Roerecke M, Tallon JM, et al. Cannabis and traffic collision risk: findings from a case-crossover study of injured drivers presenting to emergency departments. Int J Public Health. 2014;59:395-404. doi:10.1007/ s00038-013-0512-z.

9. Desrosiers NA, Ramaekers JG, Chauchard E, Gorelick DA, Huestis MA. Smoked cannabis' psychomotor and neurocognitive effects in occasional and frequent smokers. J Anal Toxicol. 2015;39:251-61. doi:10.1093/jat/bkv012.

10. Wong K, Brady J, Li G. Establishing legal limits for driving under the influence of marijuana. Inj Epidemiol. 2014;1:26. doi:10.1186/ s40621-014-0026-Z

11. Huestis MA. Human cannabinoid pharmacokinetics. Chem Biodivers. 2007;4:1770-804. doi:10.1002/cbdv.200790152.

12. Kelly P, Jones RT. Metabolism of tetrahydrocannabinol in frequent and infrequent marijuana users. J Anal Toxicol. 1992;16:228-35. doi:10.1093/jat/16.4.228.

13. Toennes SW, Ramaekers JG, Theunissen EL, Moeller MR, Kauert GF. Comparison of cannabinoid pharmacokinetic properties in occasional and heavy users smoking a marijuana or placebo joint. J Anal Toxicol. 2008;32:470-7. doi:10.1093/jat/32.7.470. 
14. Skopp G, Pötsch L. Cannabinoid concentrations in spot serum samples $24-48$ hours after discontinuation of cannabis smoking. J Anal Toxicol. 2008;32:160-4. doi:10.1093/jat/32.2.160.

15. Desrosiers NA, Himes SK, Scheidweiler KB, Concheiro-Guisan M, Gorelick DA, Huestis MA. Phase I and II cannabinoid disposition in blood and plasma of occasional and frequent smokers following controlled smoked cannabis. Clin Chem. 2014;60:631-43. doi:10.1373/clinchem.2013.216507.

16. Daldrup T, Käferstein H, Köhler H, Maier R-D, Musshoff F. Deciding between one off/occasional and regular cannabis consumption. Blutalkohol. 2000;37:39-47.

17. Fabritius M, Favrat B, Chtioui H, Battistella G, Annoni JM, Appenzeller M, et al. THCCOOH concentrations in whole blood: are they useful in discriminating occasional from heavy smokers? Drug Test Anal. 2014;6:155-63. doi:10.1002/dta.1581.

18. Fabritius M, Augsburger M, Chtioui H, Favrat B, Giroud C. Fitness to drive and cannabis: validation of two blood $\mathrm{THCCOOH}$ thresholds to distinguish occasional users from heavy smokers. Forensic Sci Int. 2014;242:1-8. doi:10.1016/j.forsciint.2014.05.014.

19. Schwope DM, Karschner EL, Gorelick DA, Huestis MA. Identification of recent cannabis use: whole-blood and plasma free and glucuronidated cannabinoid pharmacokinetics following controlled smoked cannabis administration. Clin Chem. 2011;57: 1406-14. doi:10.1373/clinchem.2011.171777.

20. Wall ME, Taylor HL. Conjugation of acidic metabolites of $\Delta-8$ and $\Delta$-9-THC in man. In: Harvey DJ, editor. Marihuana ' 84. Proceedings of the Oxford Symposium on Cannabis. Oxford: IRL Press; 1985. p. 69-76.

21. Mazur A, Lichti CF, Prather PL, Zielinska AK, Bratton SM, GallusZawada A, et al. Characterization of human hepatic and extrahepatic UDP-glucuronosyltransferase enzymes involved in the metabolism of classic cannabinoids. Drug Metab Dispos. 2009;37:1496504. doi:10.1124/dmd.109.026898.

22. Guillemette C. Pharmacogenomics of human UDPglucuronosyltransferase enzymes. Pharmacogenomics J. 2003;3: 136-58. doi:10.1038/sj.tpj.6500171.

23. Staub C. Chromatographic procedures for determination of cannabinoids in biological samples, with special attention to blood and alternative matrices like hair, saliva, sweat and meconium. J Chromatogr B Biomed Sci Appl. 1999;733:119-26. doi:10.1016/ S0378-4347(99)00249-2.

24. Fabritius M, Staub C, Giroud C. Analyse des cannabinoïdes par spectrométrie de masse en mode tandem. Ann Toxicol Anal. 2011;23:21-35. doi:10.1051/ata/2011104.

25. Schwope DM, Scheidweiler KB, Huestis MA. Direct quantification of cannabinoids and cannabinoid glucuronides in whole blood by liquid chromatography-tandem mass spectrometry. Anal Bioanal Chem. 2011;401:1273-83. doi:10.1007/s00216-011-5197-7.

26. Gomes RL, Meredith W, Snape CE, Sephton MA. Analysis of conjugated steroid androgens: deconjugation, derivatisation and associated issues. J Pharm Biomed Anal. 2009;49:1133-40. doi:10. 1016/j.jpba.2009.01.027.

27. Schwilke EW, Schwope DM, Karschner EL, Lowe RH, Darwin WD, Kelly DL, et al. Delta9-tetrahydrocannabinol (THC), 11-hydroxy-THC, and 11-nor-9-carboxy-THC plasma pharmacokinetics during and after continuous high-dose oral THC. Clin Chem. 2009;55:2180-9. doi:10.1373/clinchem.2008.122119.

28. Kemp PM, Abukhalaf IK, Manno JE, Manno BR, Alford DD, McWilliams ME, et al. Cannabinoids in humans. II. The influence of three methods of hydrolysis on the concentration of THC and two metabolites in urine. J Anal Toxicol. 1995;19:292-8. doi:10. 1093/jat/19.5.292.
29. Fabritius M, Staub C, Mangin P, Giroud C. Analysis of cannabinoids in oral fluid by liquid chromatography-tandem mass spectrometry. Forensic Toxicol. 2013;31:151-63. doi:10.1007/s11419012-0168-z.

30. Skopp G, Pötsch L. Stability of 11-nor-delta(9)-carboxy-tetrahydrocannabinol glucuronide in plasma and urine assessed by liquid chromatography-tandem mass spectrometry. Clin Chem. 2002;48: 301-6.

31. Gronewold A, Skopp G. A preliminary investigation on the distribution of cannabinoids in man. Forensic Sci Int. 2011;210:e7-11. doi:10.1016/j.forsciint.2011.04.010.

32. Scheidweiler KB, Desrosiers NA, Huestis MA. Simultaneous quantification of free and glucuronidated cannabinoids in human urine by liquid chromatography tandem mass spectrometry. Clin Chim Acta. 2012;413:1839-47. doi:10.1016/j.cca.2012.06.034.

33. Felli M, Martello S, Chiarotti M. LC-MS-MS method for simultaneous determination of $\mathrm{THCCOOH}$ and $\mathrm{THCCOOH}$-glucuronide in urine: application to workplace confirmation tests. Forensic Sci Int. 2011;204:67-73. doi:10.1016/j.forsciint.2010.05.004.

34. Food and Drug Administration (2001) Guidance for industry: bioanalytical method validation. http://www.fda.gov/downloads/ Drugs/.../Guidances/ucm070107.pdf. Accessed 28 Sept 2015.

35. European Medicines Agency (2011) Guideline on bioanalytical method validation. http://www.ema.europa.eu/docs/en_GB/ document library/Scientific guideline/2011/08/WC500109686. pdf. Accessed 28 Sept 2015.

36. Almeida AM, Castel-Branco MM, Falcão AC. Linear regression for calibration lines revisited: weighting schemes for bioanalytical methods. J Chromatogr B Anal Technol Biomed Life Sci. 2002;774:215-22. doi:10.1016/S1570-0232(02)00244-1.

37. König S, Aebi B, Lanz S, Gasser M, Weinmann W. On-line SPE LC-MS/MS for the quantification of delta9-tetrahydrocannabinol (THC) and its two major metabolites in human peripheral blood by liquid chromatography tandem mass spectrometry. Anal Bioanal Chem. 2011;400:9-16. doi:10.1007/s00216-011-4708-x.

38. Brunetto Mdel R, Contreras Y, Delgado Y, Gallignani M, Estela JM, Martin VC. Development and validation of a rapid columnswitching high-performance liquid chromatographic method for the determination of lamotrigine in human serum. J Chromatogr Sci. 2009;47:478-84. doi:10.1093/chromsci/47.6.478.

39. Wickremsinhe ER, Lee LB, Schmalz CA, Torchia J, Ruterbories KJ. High sensitive assay employing column switching chromatography to enable simultaneous quantification of an amide prodrug of gemcitabine (LY2334737), gemcitabine, and its metabolite dFdU in human plasma by LC-MS/MS. J Chromatogr B Anal Technol Biomed Life Sci. 2013;932:117-22. doi:10.1016/j.jchromb.2013. 06.008 .

40. Satinsky D, Havlikova L, Solich P. HPLC column-switching technique for sample preparation and fluorescence determination of propranolol in urine using fused-core columns in both dimensions. Anal Bioanal Chem. 2013;405:6583-7. doi:10.1007/s00216-0137098-4.

41. Alves MN, Zanchetti G, Piccinotti A, Tameni S, De Martinis BS, Polettini A. Determination of cocaine and metabolites in hair by column-switching LC-MS-MS analysis. Anal Bioanal Chem. 2013;405:6299-306. doi:10.1007/s00216-013-7046-3.

42. Scheidweiler KB, Schwope DM, Karschner EL, Desrosiers NA, Gorelick DA, Huestis MA. In vitro stability of free and glucuronidated cannabinoids in blood and plasma following controlled smoked cannabis. Clin Chem. 2013;59:1108-17. doi:10. 1373/clinchem.2012.201467. 